\title{
THE IMPACT OF ENVIRONMENTAL CONSTRUCTION ON THE SPATIAL CONFIGURATION OF TRADITIONAL IRANIAN HOUSING (CASE STUDY: COMPARISON OF DEZFUL AND BOROUJERD TRADITIONAL HOUSING)
}

\author{
Pedram HESSARI (D) ${ }^{1,}$, Farhad CHEGENI (1) ${ }^{2}$ \\ ${ }^{1}$ University of Torbat Heydarieh, Torbat Heydarieh, Iran \\ ${ }^{2}$ Jundi-Shapur University of Technology, Dezful, Iran
}

Received 18 January 2021; accepted 19 March 2021

\begin{abstract}
The cities of Dezful and Boroujerd can be considered a treasure trove of traditional houses in Iran whose social, functional, and cultural roots are reflected in their architectural body. Traditional housing includes and expresses the lifestyles and behavioral systems of its inhabitants. Therefore, by analyzing the spatial structure in different traditional dwellings, we can understand the structural differences in them. The main purpose of this study is to identify and express the structure and spatial differences in traditional housing in Dezful and Boroujerd, which have many differences in terms of environmental structure. This study seeks to answer the question: What are the differences between structural patterns and spatial configuration in traditional housing in Dezful and Boroujerd? The method of this research is generally qualitative and software that includes analytical-descriptive approaches and logical reasoning. First, using observation, field survey, and library studies, the desired maps are obtained and the research parameters such as spatial integrity, visual privacy and control, and access are determined. In the next step, the maps of selected research houses are analyzed and analyzed in Space Syntax software, which is specialized software for space syntax, and the patterns of spatial configuration in traditional houses of Dezful and Boroujerd are expressed. The results show that the permeability and readability of more spaces due to the depth of each space and better spatial perception by individuals in traditional houses in Dezful is more than traditional houses in Boroujerd. In contrast, in traditional houses in Boroujerd, spatial stratification and spatial hierarchy, the creation of public and private layers due to the shape and type of housing, and also environmental security in the residential complex is more than the examples of traditional housing in Dezful.
\end{abstract}

Keywords: spatial configuration, space syntax, traditional housing of Dezful and Boroujerd, spatial integrity, visual layering, control, access.

\section{Introduction}

Traditional Iranian residential architecture is full of valuable examples of identity housing. Remains of historical periods in different cities of Iran are evidence of this claim (Hajian et al., 2020, p. 112). Various researches have been done in the field of recognizing relations and spatial structure in traditional houses of Iran and its effect on the ways and system of people's lives, which in all cases has tried to recognize the body and architecture of traditional houses using a mental approach (Mozaffar et al., 2012, p. 36). This is while many theorists in the cognitive domains of environment and behavior, lifestyles, and patterns that govern it as the main way to express the introduction of housing (Madahi \& Memarian, 2019, p. 69). One of the most important things that can be used to identify the valuable concepts of residential culture in traditional Iranian residential architecture is the analysis of the physical structure of housing in terms of understanding the spatial structure and its spatial configuration. Traditional Iranian houses have unique features that it is not possible to recognize these features only by physical examination and with tools such as plan, etc. To facilitate the spatial analysis of traditional houses, there is a need for a tool to translate space into simple and understandable language. To understand and explain the structure and configuration of space, one must look for an appropriate method that responds to environmental characteristics. To quantify and more concretely understand the structure and configuration of space, there are various methods, most of which rely on visual and physical aspects, metric distances, and

${ }^{*}$ Corresponding author. E-mail: p.hessari@torbath.ac.ir 
geometric aspects of configuration. These methods are largely incapable of recognizing the relationship of "spatial configuration" in traditional homes. One of the successful theories and methods that study the structure and configuration of urban and residential space is the theory of spatial syntax (Mohareb, 2009, p. 254). The syntax of space is a theory and a tool for analysis in architecture and urban planning. This attitude was founded by Hillier in London in the early 1980s (Montello, 2007, p. 10). The importance of knowing the spatial configuration and its method, i.e. the way of space, is determined when it can be used to understand the social and cultural logic of the formation of different spaces in the spatial configuration of one or more sets (Vannes, 2011, p. 168). Most research in the field of spatial configuration has provided a general definition of this concept and the variables that are used to understand this concept through the method of space syntax. Therefore, this study intends to try to extract the similarities and differences in the spatial configuration of traditional houses by recognizing the concept of spatial configuration and its various characteristics that are obtained through the method of space syntax. The two cities of Dezful and Boroujerd have two different climates. This analysis can be used to determine the differences in the structure and spatial configuration of traditional houses in Dezful and Boroujerd. Therefore, the main research questions are:

- How to use the concept of spatial configuration to determine the differences due to the physical structure in the two traditional houses of Boroujerd and Dezful?

- What are the differences between the structural patterns and spatial configuration used in traditional houses in Dezful and Boroujerd?

\section{Research background}

Although several decades have passed since the study of understanding the concept of spatial configuration and the method used in this concept, i.e. the syntax of space, still different, and new results and suggestions are presented in this regard. According to the research topic, which is derived from the knowledge of spatial configuration in traditional housing, the research background in this research (Table 1) deals with a spatial configuration in housing.

In most of the reviewed studies, the spatial configuration in traditional houses has been analyzed by analyzing a few case studies and using spatial configuration variables obtained using the space syntax method and applied individually. However, in addition to accurately understanding the concept of spatial configuration and its method, namely the syntax of space, the study was conducted to measure this concept in the traditional houses of Boroujerd and Dezful, which differ in terms of structure and characteristics of the environment.

\subsection{Theoretical foundations}

\subsubsection{Understanding the concept of traditional housing}

The word housing is the name of a place from the root of dwelling, which means to stop. However, this term carries with it a diverse set of physical and conceptual concepts. In the statement of the second session of the Human Summit Conference in Istanbul, Turkey, instead of using the word housing, the phrase "suitable shelter" was used (Habitat, 2003, p. 22). It explains that "adequate shelter is more than one roof over each person's head." Rather, it means proper

Table 1. Research background, research on housing spatial configuration (source: compiled by the authors)

\begin{tabular}{|c|c|c|c|}
\hline Scope of study & Year & Researchers & Row \\
\hline $\begin{array}{l}\text { Understanding the spatial structure of Shiraz native houses using the concept of the } \\
\text { spatial configuration of the environment }\end{array}$ & 2020 & Bazai et al. & 1 \\
\hline $\begin{array}{l}\text { Understanding spatial configuration in traditional and contemporary houses in } \\
\text { Boroujerd }\end{array}$ & 2020 & Chegeni et al. & 2 \\
\hline $\begin{array}{l}\text { Recognition of spatial communication in traditional housing in Kashan using } \\
\text { nehospace tools }\end{array}$ & 2019 & Sa'adati Waqar et al. & 3 \\
\hline $\begin{array}{l}\text { Reading the spatial organization and way of life in the native houses of humanity } \\
\text { using the method of space syntax }\end{array}$ & 2017 & $\begin{array}{l}\text { Madahi and } \\
\text { Memarian }\end{array}$ & 4 \\
\hline Recognition of spatial configuration in Qeshm native housing & 2016 & $\begin{array}{l}\text { Tabatabae Malazi and } \\
\text { Sabernejad }\end{array}$ & 5 \\
\hline Recognition of visual quality in traditional houses of Bushehr using space syntax tools & 2012 & Ali Al-Hesabi et al. & 6 \\
\hline $\begin{array}{l}\text { Recognition of form composition and zoning in Kerman native housing using the } \\
\text { concept of spatial configuration }\end{array}$ & 2012 & Kamalipour et al. & 7 \\
\hline $\begin{array}{l}\text { Recognition of behavioral patterns in traditional housing in Hamedan using the } \\
\text { concept of spatial configuration }\end{array}$ & 2016 & Alitajer and Nojoumi & 8 \\
\hline $\begin{array}{l}\text { The role of spatial arrangement in the architecture of Australian Indigenous homes } \\
\text { using the concept of configuration }\end{array}$ & 2016 & Perugia et al. & 9 \\
\hline $\begin{array}{l}\text { Recognizing privacy in traditional and modern homes in Erbil, Iraq with the help of } \\
\text { spatial configuration }\end{array}$ & 2010 & Mustafa et al. & 10 \\
\hline
\end{tabular}


privacy, accessibility, safety, occupational safety, structural stability and durability, lighting, adequate heating and ventilation, adequate infrastructure such as water resources, sanitation, and waste disposal equipment, appropriate environmental and health criteria, location, and access It is suitable for workplaces and infrastructure facilities, all of which should be available to individuals at a reasonable cost (Nasr, 2015, p. 69). Traditional Iranian housing is one of the most important manifestations of Iranian architecture so that it has always been able to have high desirability by establishing a proper relationship with the lifestyle and social conditions of its time (Asefi \& Imani, 2016, p. 60). Traditional housing is a generalized housing that has been born from popular architecture and it can be considered as an advanced form of the natural architecture of a region that has been formed to culture, a climate of a region (Zolfagharzadeh \& Hessari, 2014, p. 42). Several indicators and components are influential in the emergence of traditional housing, as shown in Table 2.

\subsubsection{Spatial configuration}

In the late 1970s, Professor Bill Hillier and Julien Hansen proposed the theory of spatial configuration to understand the spatial structure of space, based on which they analyzed the interaction between the configuration of space and the social organization of cities. According to this theory, the relationship between activity and space can be defined more individually than in the properties of space, it can be understood and defined in the existing connections between spaces or the space organization as well as the connections between audiences and social interactions (Siadatian \& Pourjafar, 2015, p. 34). Spatial configuration analysis deals with how spaces are arranged next to each other and how they interact with each other. In other words, any change in the map and structure of space will make changes in the spatial configuration relations of the set of spaces (Sajjadzadeh et al., 2017, p. 6). The main purpose of this concept is to strengthen and emphasize the role of spatial communication, which can give each space a social relation, commensurate with behavior. It is important to understand that spatial configuration is one of the most important topics for recognizing and understanding the relationship between spaces in residential architecture (Rajaei et al., 2018, p. 39). In general, spatial configuration means how the spaces are arranged next to each other and how they interact with each other. Thus, it can be concluded that any change in the arrangement of spaces will cause changes in the overall level of spatial configuration and also affect the amount and manner of activities in space (Jeong et al., 2015, p. 151). Spatial configuration believes that space is the core of how social and cultural events occur. Since space itself is formed through social, cultural, and economic processes, it is usually considered as a platform for social and cultural activities to the extent that its usual form is not considered and is invisibly assumed and felt (Rodriguez et al., 2012). This concept believes that space is the core of how social and cultural events take place, although since space itself is formed through social, cultural, and economic processes, it is often considered as a platform for social and cultural activities to the extent that its form is not usually considered and is perceived and felt invisibly (Rodriguez et al., 2012). To understand and explain the spatial configuration, one must look for an appropriate method that responds to the environmental characteristics. The main method for understanding spatial configuration is the syntax method of space. Syntax of space is a theory and a set of methods about space that is based on two ideas:

- Space is not in the background of activity but is an intrinsic aspect of the activity that is done in three ways: moving within space, interacting with other people in space, and seeing space from a point within it.

- Human space is not limited to one space, but it is from the interaction between different spaces that the general system is formed and it is called "spatial configuration" and is measured through the syntactic method of space (Estaji, 2014, p. 32).

The spatial syntax method is a developed approach that is used in the analysis of the spatial structure of manmade environments (Manum, 2009, p. 3) that aims to describe spatial models and display these models in graphic forms and thus facilitate scientific interpretations of the desired spaces in a spatial set. This method is also referred to as the "space syntax technique" in architecture and urban planning. In this technique, by converting the spatial structure of the artificial environment into graphic patterns, the relations are presented in the form of mathematical data, so that by analyzing this data, we can understand the interrelationships between the body of the environment and the behavior of its users. The most important tool used to analyze the structure of spatial configuration

Table 2. Effective indicators in traditional Iranian housing (source: authors, based on a study by Heidari et al., 2018)

\begin{tabular}{|l|c|c|}
\hline \multicolumn{1}{|c|}{ Visibility in traditional housing } & Characteristics & Row \\
\hline $\begin{array}{l}\text { Lack of direct communication with outdoor spaces and organizing spaces around } \\
\text { the central courtyard of the building }\end{array}$ & Introversion \\
\hline Creating territory in private and public spaces through accesses & Hierarchy & 2 \\
\hline Do not use and create entrances in the main spaces directly & Privacy & 3 \\
\hline Place windows in the walls so that they do not overlook the main spaces & Location & 4 \\
\hline Use the yard to control optimal visual access and prevent unwanted access & There was no aristocracy & 5 \\
\hline
\end{tabular}


by space syntax is Depthmnap software. The software, developed by Turner and colleagues at the London Academy of Sciences, allows researchers to analyze space at all micro and macro scales with much higher accuracy and with much higher indicators (Pinelo \& Turner, 2010). In this method, a spatial configuration is analyzed using interconnection, visual access, isovist, and visual depth (metric depth) indicators.

Integration: Each space in the spatial configuration means the degree of continuity or separation of that space relative to other spaces in that configuration active to other spaces in that configuration. Space has a lot of Integration that is more integrated with other spaces. Space is highly Integration that is more integrated with other spaces (Hillier et al., 1984). Connecting spaces means the number of connections of each space with other spaces in the configuration. This variable is also related; this means that the multiplicity of connections between spaces increases the degree of Integration and integrity of the space. With the help of these two indicators (Integration and connection), the degree of spatial integrity in the spaces of a complex can be measured (Ostwald, 2011, p. 739).

Isovist: Isovist means the study of a series of visible points from a particular point in space. This method is a tool for the permanent recording of information from the environment (Tandy, 1967). Isovist has various parts in syntactic computer tools that are used to record the visual dimensions of the environment as accurately as possible (Heidari \& Peyvastegar, 2018, p. 46). In the present study, due to its nature, which is to study the dimensions of the environment, environmental Isovist (the study of the amount of environment seen from the entire perimeter or the boundary of the building in different parts of the space in meters) will be used. This variable in the graph system determines the visual volume of the eye cone of individuals at the moment of being placed in a single set. With the help of this variable in space technology software, the amount of control and access in spaces can be determined.

Visual layering: Visual layering in space can be evaluated through the concept of visible space. Visible space, or the surface that can be seen from anywhere, is part of the space syntax technique, which measures users' perception of space and is an important tool in how people perceive and act towards space (Emo, 2015, p. 11). To determine the visual privacy in the houses, in the syntax analysis of the space and Depthmap software, a step depth diagram was drawn, and to check the physical depth, a metric step diagram was drawn (Turner, 2004, p. 12).

There are three approaches to plan analysis in this method, which are: axial, convex, and graph, which are briefly described.

Axial approach: In this system, a connection graph is defined based on how each line interacts with the surrounding lines and is typically used for textures in the city, village, or neighborhood unit. Convex approach: Convex space is a space that does not intersect the line connecting the two points of space, the surrounding environment of the space. Analytical method "Convex map" is mostly used in environments where there is free space nonlinearly. An example is the interior of a building where most of the rooms are spread in two directions and parallel. Graph metric approach: Using visual analysis, examines the main indicators of the syntactic attitude of space. The output of this analysis is a map in which each index is in the red to blue color spectrum that expresses the range of the highest to the lowest of the desired index (Klarqvist, 1993, p. 11). In this research, considering that the subject of analysis is not in the context and the city and the analysis of the residential plan is considered, two approaches of a convex and exponential graph are used.

\subsubsection{Recognition of the studied areas}

To identify the limitations of the research, first, the selected cities of the research are briefly introduced and in the next step, the structural features of the cities are stated. Dezful is a city with a hot and semi-arid climate in southwestern Iran, which is located along the Dez River in the plains of Khuzestan province. This city is 143 meters above sea level and is one of the northern cities of Khuzestan province. The population of this city is 444,400 people (Statistics Center of Iran, 2016). The traditional architecture of Dezful has remarkable antiquity so that the most beautiful brickwork is related to this city and hundreds of patterns and colors can be seen in the brickwork of this city (Momeni et al., 2020, p. 15). Boroujerd city with a cold and mountainous climate is one of the cities of Lorestan province, which is 1560 meters above sea level. The population of Boroujerd city is 334,000 people. Boroujerd can be considered as one of the most important historical cities of Iran from the point of view of urban planning and architecture with architectural elements such as the Grand Mosque, which is more than a thousand years old. That is why all the texts of the early Islamic centuries refer to it as one of the important cities of "Ajam Iraq" (Goodarzi \& Jalili, 2014, p. 3). To better understand the traditional buildings of Dezful and Boroujerd, the characteristics of traditional housing in both cities are given in Table 3 .

\subsubsection{Selected case studies}

To conduct this part of the research, ten houses in the historical context of Dezful and Boroujerd cities have been selected, which exist as a single building in different parts of the traditional context (Table 4). Of these, five houses are related to the traditional buildings of Dezful and the other five are related to traditional buildings in the city of Boroujerd. The buildings were first identified, harvested, redrawn, and modified in the context. After identifying and identifying the houses, their spatial configuration was performed by Space Syntex software. Also, for more accurate research, all selected houses are single-yard type. It is necessary to explain that in the analysis of the spatial configuration of the houses, the floor plan of the ground floor of the houses has been analyzed using the syntactic method. 
Table 3. Physical knowledge of traditional housing texture in Dezful and Boroujerd (source: compiled by the authors)

\begin{tabular}{|c|c|c|c|c|c|}
\hline \multicolumn{5}{|c|}{ Specifications } & Cities \\
\hline Patterns used in housing & $\begin{array}{l}\text { Number of housing } \\
\text { floors }\end{array}$ & Ron architecture & Construction period & $\begin{array}{c}\text { General } \\
\text { specifications }\end{array}$ & \multirow{6}{*}{ Dezful } \\
\hline \multirow{5}{*}{$\begin{array}{l}\text { - Traditional compact and } \\
\text { dense texture } \\
\text { - The general form of a com- } \\
\text { pact and heavy cube } \\
\text { - They are semi-introverted } \\
\text { - Construction of a grille on } \\
\text { the roof } \\
\text { - Windows higher than hu- } \\
\text { man height }\end{array}$} & $\begin{array}{l}\text { Often two floors, } \\
\text { rarely three floors }\end{array}$ & Ron Isfahani & $\begin{array}{c}\text { From Safavid era to } \\
\text { Qajar }\end{array}$ & & \\
\hline & Index decorations & $\begin{array}{l}\text { Spatial index } \\
\text { elements }\end{array}$ & Space structure & \multirow[t]{2}{*}{ Physical-spatial } & \\
\hline & - & Shoadon & $\begin{array}{l}\text { Open and semi-open } \\
\text { and closed spaces }\end{array}$ & & \\
\hline & Head & Roofing & Door and window & \multirow{2}{*}{$\begin{array}{l}\text { Additional } \\
\text { elements }\end{array}$} & \\
\hline & $\begin{array}{c}\text { Significant } \\
\text { entrances and all } \\
\text { brick }\end{array}$ & $\begin{array}{l}\text { They are brick and } \\
\text { index }\end{array}$ & It was made of wood & & \\
\hline Patterns used in housing & $\begin{array}{l}\text { Number of housing } \\
\text { floors }\end{array}$ & Ron architecture & Construction period & \multirow[t]{2}{*}{$\begin{array}{c}\text { General } \\
\text { specifications }\end{array}$} & \multirow{6}{*}{ Borujerd } \\
\hline \multirow{5}{*}{$\begin{array}{l}\text { - Compact traditional tex- } \\
\text { ture } \\
\text { - The house is level with the } \\
\text { ground } \\
\text { - Complete introspection of } \\
\text { houses } \\
\text { - Lack of visual continuity } \\
\text { with the outside }\end{array}$} & $\begin{array}{l}\text { Often two floors } \\
\text { and rarely three } \\
\text { floors }\end{array}$ & Ron is right & Of Zandieh to Qajar & & \\
\hline & Index decorations & $\begin{array}{c}\text { Spatial index } \\
\text { elements }\end{array}$ & Space structure & \multirow[t]{2}{*}{ Physical-spatial } & \\
\hline & - & $\begin{array}{l}\text { Moonlight and } \\
\text { porch }\end{array}$ & $\begin{array}{l}\text { Open and semi-open } \\
\text { and closed spaces }\end{array}$ & & \\
\hline & Head & Roofing & Door and window & \multirow{2}{*}{$\begin{array}{l}\text { Additional } \\
\text { elements }\end{array}$} & \\
\hline & $\begin{array}{l}\text { Often made of } \\
\text { bricks }\end{array}$ & $\begin{array}{l}\text { Brick and mouse } \\
\text { teeth }\end{array}$ & Made of wood & & \\
\hline
\end{tabular}

Table 4. Selected research houses (source: compiled by the authors)

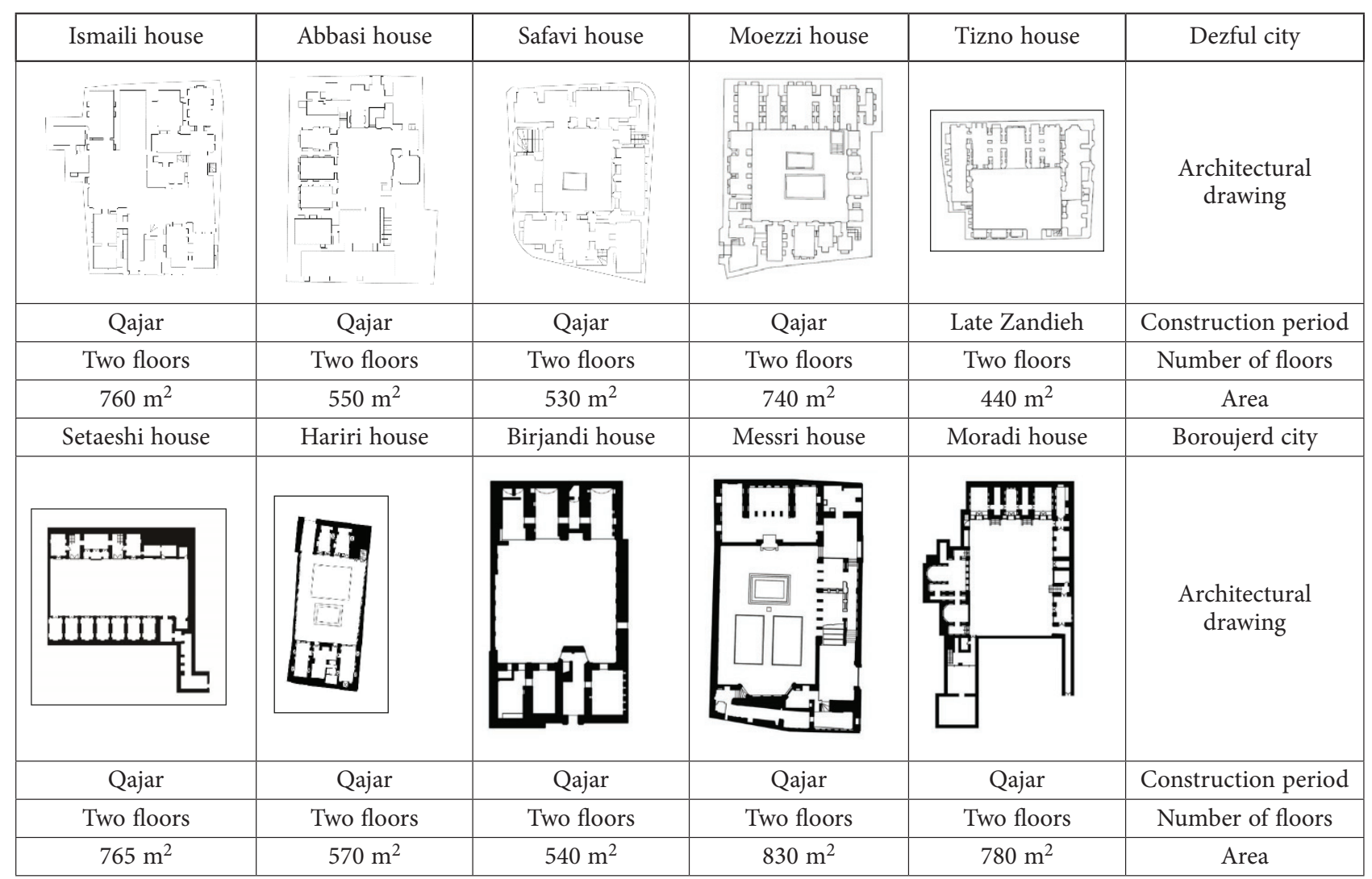




\section{Methodology and/or theoretical framework}

The method of this research is qualitative and software that includes analytical-descriptive approaches and logical reasoning. In simpler language, this research is divided into two main parts in terms of research method. The first part of the research, which has a qualitative approach, consists of two steps. The first step involves library and documentary studies. In this step, by referring to the primary sources and documents, the concepts of traditional houses and houses, spatial configuration and its method, space as well as research contexts, which are the cities of Boroujerd and Dezful, are discussed. The second step also involves field observation and harvesting. In this step, according to the research topic, ten traditional houses in Boroujerd and Dezful have been randomly selected. The second part

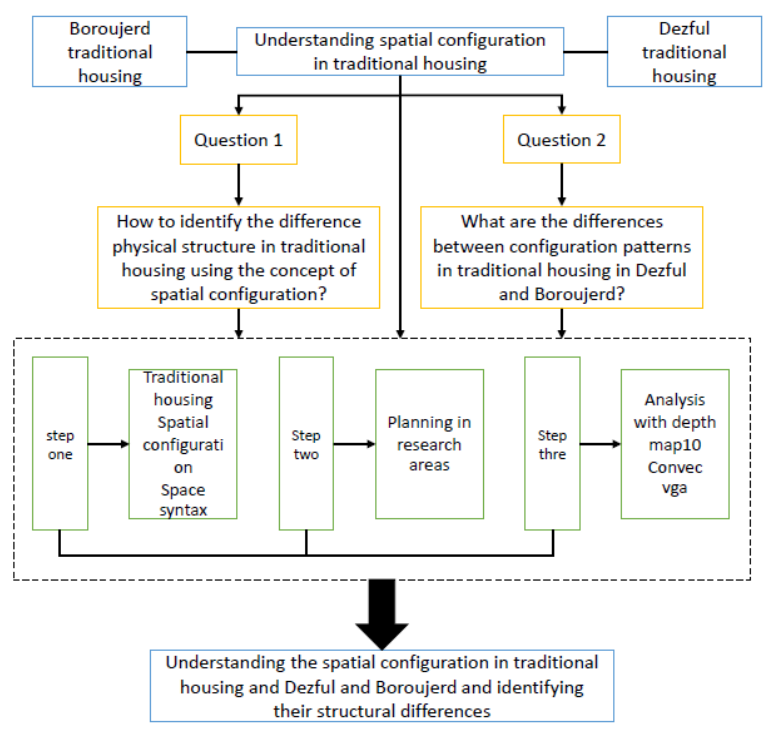

Figure 1. Research process

(source: compiled by the authors) involves a quantitative approach. In this section, the maps of the selected houses in different scales are analyzed for space configuration. After modeling the drawings in AutoCAD software, this method is obtained and the drawings are entered into Space Syntax software. This software calculates the space configuration variables resulting from the nehospace method for all houses. Finally, the obtained results are expressed using logical reasoning. After these steps and analysis of the maps in Space Syntex software, the configuration of the spaces in the selected research houses is analyzed using comparative comparison.

\section{Results of the research}

In this section (Table 5), according to library plans and field observations, six samples of traditional houses in Dezful and Boroujerd were selected. And all the effective factors in spatial configuration and space syntax variables in these plans were examined.

The spatial syntax is a set of theories and methods that analyze spaces in a spatial set. And it can be considered as one of the most important contemporary methods (on the scale of architecture and urban planning) that explains how the configuration of space, social organization, and social behaviors interact. The syntax method of the space is modeled and analyzed by the arrangement method and with the help of the display of connected graphs (a branch of discrete mathematics) how the spatial configuration is arranged by how the spaces are arranged next to each other and their effect on activities and movement of people (Mollazadeh et al., 2012, p. 82). After analyzing the graph of the variables of selected houses in Dezful and Boroujerd, a quantitative analysis of the spatial configuration of houses is performed. It should be noted that to quantify the spatial configuration, the average of the variables has been calculated.

Table 5. Quantitative and numerical analysis of the spatial configuration of research houses (source: compiled by the authors)

\begin{tabular}{|c|c|c|c|c|c|c|c|}
\hline $\begin{array}{c}\text { Control and } \\
\text { access }\end{array}$ & \multicolumn{2}{|c|}{ Visual privacy } & \multicolumn{2}{c|}{ Spatial readability } & \multicolumn{3}{c|}{ Research variables } \\
\hline $\begin{array}{c}\text { (isovist } \\
\text { perimeter) }\end{array}$ & (metric depth) & (step depth) & (connectivity) & (integration) & House numbers & $\begin{array}{c}\text { House } \\
\text { names }\end{array}$ & $\begin{array}{c}\text { Research } \\
\text { cities }\end{array}$ \\
\hline $978 / 20$ & $81 / 54$ & $1 / 42$ & $3296 / 96$ & $1 / 62$ & House No. 1 & Tizno \\
\hline $1404 / 68$ & $92 / 76$ & $1 / 37$ & $2193 / 43$ & $1 / 86$ & House No. 2 & Moezzi \\
\hline $1112 / 13$ & $90 / 54$ & $1 / 40$ & $2216 / 19$ & $1 / 58$ & House No. 3 & Safavi & Dezful city \\
\hline $1287 / 58$ & $79 / 61$ & $1 / 59$ & $2800 / 05$ & $1 / 74$ & House No. 4 & Abbasi \\
\hline $1441 / 98$ & $89 / 35$ & $1 / 53$ & $1987 / 78$ & $1 / 82$ & House No. 5 & Ismaili \\
\hline $580 / 83$ & $58 / 86$ & $1 / 29$ & $2268 / 31$ & $2 / 28$ & House No. 1 & Birjandi \\
\hline $543 / 30$ & $55 / 90$ & $1 / 21$ & $1377 / 39$ & $1 / 94$ & House No. 2 & Moradi \\
\hline $626 / 90$ & $60 / 61$ & $1 / 13$ & $2321 / 73$ & $2 / 42$ & House No. 3 & Messri \\
\hline $590 / 98$ & $68 / 68$ & $1 / 12$ & $1987 / 36$ & $2 / 23$ & House No. 4 & Hariri \\
\hline $758 / 74$ & $64 / 59$ & $1 / 32$ & $1875 / 45$ & $1 / 98$ & House No. 5 & Setaeshi \\
\hline
\end{tabular}




\section{Discussion and interpretation of results obtained}

Spatial integrity: The concept of spatial integrity is related to the concepts of space separation and cohesion. This concept clearly expresses the principles of architecture such as spatial hierarchy, privacy, and visibility. To define the concept of spatial integrity in the configuration of traditional houses, interconnection and connection variables are used in the nehospatial method. The correlation variable has a direct effect on the two factors of hierarchy and spatial stratification. As can be seen from Figure 1 of the study, the amount of interconnection in traditional houses in Dezful is significantly different from traditional houses in Boroujerd. This fact indicates that in traditional houses of Boroujerd, principles such as spatial stratification and spatial hierarchy, environmental security, and control over spaces have been paid more attention.

The concept of spatial integrity is also related to the connection variable. The connection variable is directly related to the concept of permeability in homes and generally means a certain amount of space in a residential unit or complex that can be perceived by the visual power (Penone et al., 2012, p. 130). According to Figure 2 of the research, the connection of traditional houses in Dezful is significantly more than traditional houses in Boroujerd. This fact indicates that the traditional houses of Dezful have better permeability than the traditional houses of Boroujerd and the control over the spaces in these houses is more suitable than the traditional houses of Boroujerd.

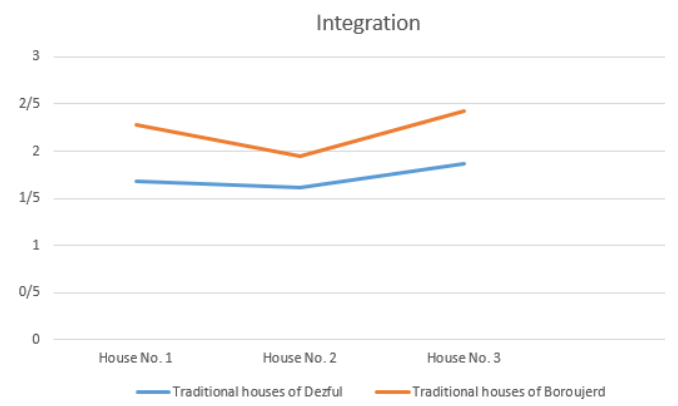

Figure 2. Measurement of integration in traditional houses of Dezful and Boroujerd (source: compiled by the authors)

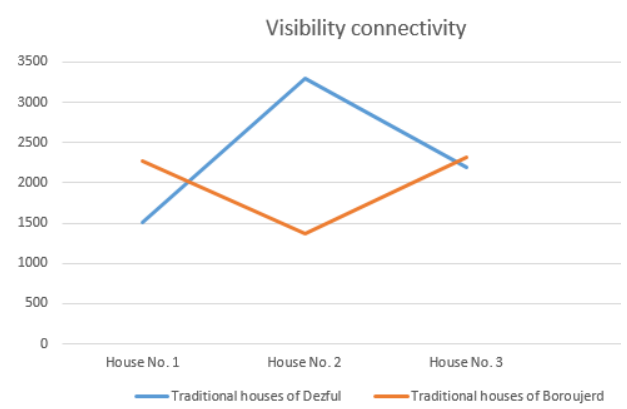

Figure 3. Measuring visual access in traditional houses of Dezful and Boroujerd (source: compiled by the authors)
Visual layering: Visual layering in spatial assemblies is the same depth in the neohospatial method. This concept is defined in the spatial configuration of a set by two variables, metric depth, and step depth. With this index, the readability in the environment can be measured. Readability rate affects issues such as space monitoring, space security, and people's satisfaction with the spaces of a collection (Weisman, 1981). Also, using this concept, visual communication and visual privacy in a collection can be measured. As shown in Figures 3 and 4, the layering and visual privacy, the feeling of satisfaction with space, and the monitoring of spaces in a complex in the traditional houses of Dezful have been observed more than the traditional houses of Boroujerd.

Control and access: The concept of control and accessibility in the spatial configuration of traditional homes is understood by the isovist variable. This variable is the field of view of the observer in a spatial complex that looks at the spaces around him from one point and indicates how much the person can see his surroundings. In general, this variable also examines the level of security in a spatial complex (Fisher \& Nasar, 1992). As shown in Figure 5, this variable is much more significant in traditional houses in Dezful than in traditional houses in Boroujerd. This fact states that the manner and position of the observer and the people in the traditional houses of Dezful to see the surroundings is better and more proportionate than the traditional houses of Boroujerd (Figures 6 and 7).

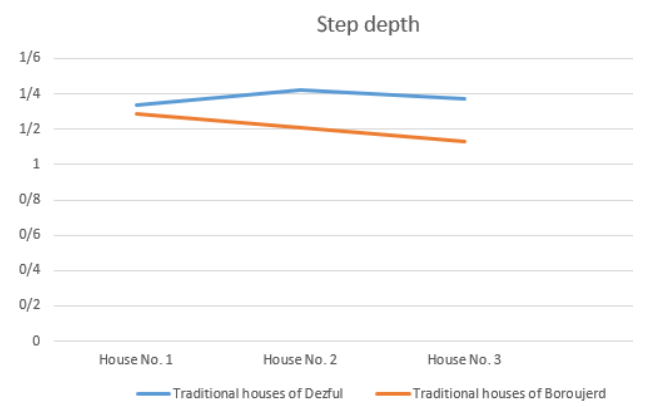

Figure 4. Measuring the depth variable in traditional houses in Dezful and Boroujerd (source: compiled by the authors)

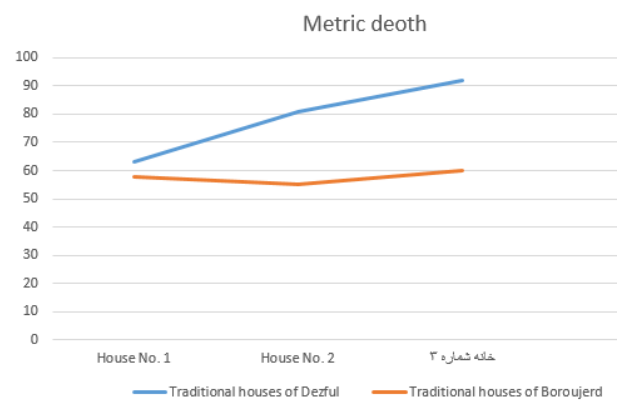

Figure 5. Measurement of metric depth variable in traditional houses of Dezful and Boroujerd (source: compiled by the authors) 


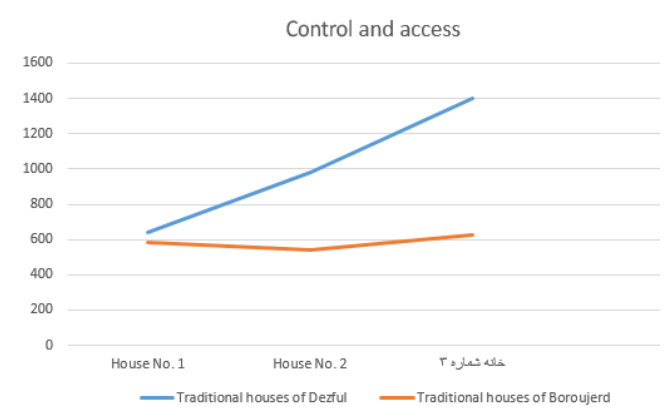

Figure 6. Measuring control and access in traditional houses in Dezful and Boroujerd (source: compiled by the authors)

\section{Conclusions}

Traditional and old houses in Iran have unique features and characteristics that recognition and discovery of these features cannot be achieved only with tools such as plans and so on. One of the most important tools and strategies in understanding the structure of traditional and old houses is the concept of spatial configuration. The spatial configuration is the result of various processes of social, cultural, economic, and physical dimensions. Comparison and understanding of spatial configuration in houses of different cities can reveal different dimensions of residential methods and principles used in these houses.

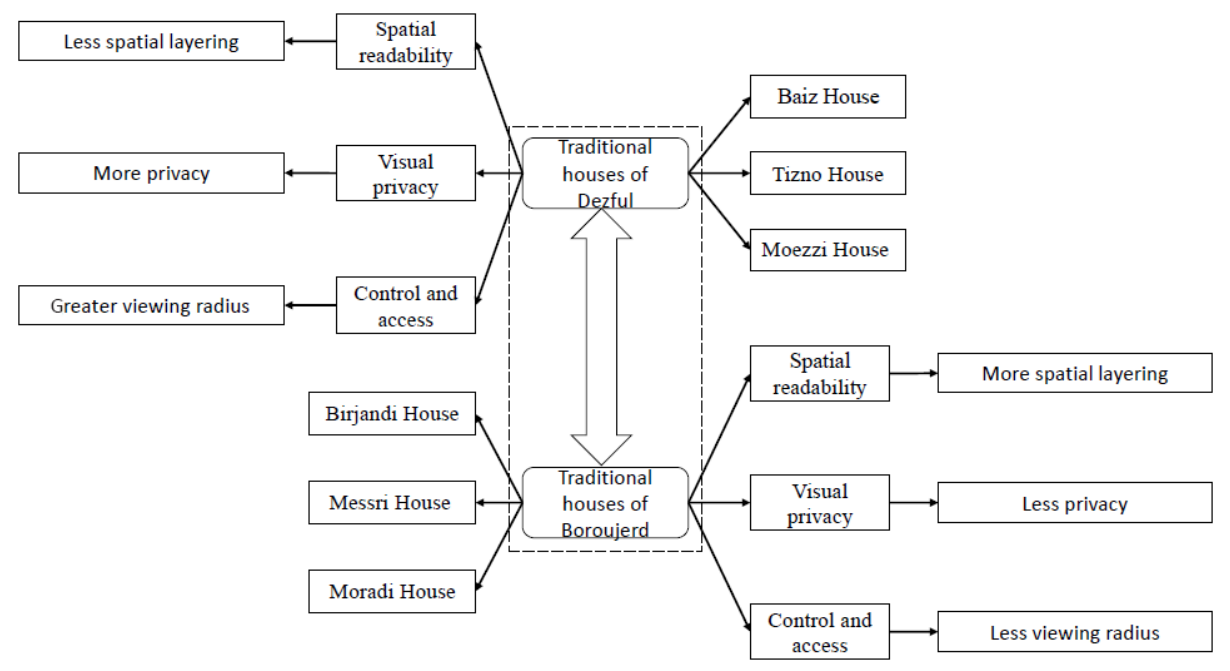

Figure 7. Recognition of the spatial configuration of traditional houses in Dezful and Boroujerd (source: compiled by the authors)

Table 6. Structural differences in the spatial configuration of traditional housing in Dezful and Boroujerd (source: compiled by the authors)

\begin{tabular}{|c|c|c|}
\hline Spatial configuration features used in traditional houses in Dezful and Boroujerd & $\begin{array}{c}\text { Spatial configuration } \\
\text { variables }\end{array}$ & Traditional houses \\
\hline $\begin{array}{l}\text { - Due to less control over the spaces, traditional houses in Dezful have more perme- } \\
\text { ability than traditional houses in Boroujerd } \\
\text { - Due to the greater depth of spaces in the complex, the length of the spaces is longer } \\
\text { and the spaces of the residential complex are more readable } \\
\text { - Existence of more space on the spaces due to the readability of the residential complex } \\
\text { - Privacy of each space of the residential complex due to the great depth and distance } \\
\text { in the residential complex } \\
\text { - There is better access to spaces in the complex due to more connection } \\
\text { - The spatial experience of the audience is better than each space in the residential } \\
\text { complex due to the legibility of the complex } \\
\text { - Spatial hierarchy and less spatial stratification in residential complexes } \\
\text { - The cone of people in the traditional houses of Dezful is more than the traditional } \\
\text { houses of Boroujerd }\end{array}$ & $\begin{array}{l}\text { Spatial readability } \\
\text { Visual privacy } \\
\text { Control and access }\end{array}$ & $\begin{array}{c}\text { Traditional houses } \\
\text { of Dezful }\end{array}$ \\
\hline $\begin{array}{l}\text { - Better connection of each space in the residential complex due to the proximity and } \\
\text { proximity of spaces in the residential complex } \\
\text { - Less privacy of traditional houses in Boroujerd than traditional houses in Dezful due } \\
\text { to the increase in area and length of more spaces } \\
\text { - Hierarchy and layering of more suitable spaces in a residential complex compared to } \\
\text { traditional houses in Dezful } \\
\text { - Proper spatial separation of traditional houses and better creation of private and pub- } \\
\text { lic layers in the plan of the complex } \\
\text { - The environmental security of the complex and consequently better control over each } \\
\text { space is more than traditional houses in Dezful } \\
\text { - Establishment and better observer status in the residential complex compared to tra- } \\
\text { ditional houses in Dezful }\end{array}$ & $\begin{array}{l}\text { Spatial readability } \\
\text { Visual privacy } \\
\text { Control and access }\end{array}$ & $\begin{array}{c}\text { Traditional houses } \\
\text { of Boroujerd }\end{array}$ \\
\hline
\end{tabular}


The present study, using the concept of spatial configuration and its method, ie space syntax, organization, and spatial structure, examined one of the most valuable architectural treasures of Iran, namely the traditional houses of Dezful and Boroujerd, which all belong to They are from the Qajar period. The main purpose of this study is to determine the differences between spatial configuration and spatial structure in traditional houses in Dezful and Boroujerd, which is obtained by the method of space syntax. This research uses the method of spatial syntax to focus on spatial communication in the whole set, not the micro-characteristics of space (form and appearance). In this regard, to identify the spatial configuration in traditional houses, ten traditional houses belonging to the Qajar period in Dezful and Boroujerd cities were examined (Table 6). The research findings indicate that:

- Regarding the concept of space integrity, traditional houses in Boroujerd have more interconnection than traditional houses in Dezful. This indicates better observance of some principles of traditional architecture in Boroujerd houses, such as spatial hierarchy and spatial layering compared to traditional houses in Dezful. How to place public and private spaces in courtyards and separate these spaces from each other in traditional houses in Boroujerd, a more appropriate layering has been provided than in traditional houses in Dezful. Also, visual access in traditional houses of Dezful is better than traditional houses in Boroujerd. That is the amount of permeability in traditional homes. And shows that the permeability of traditional houses in Dezful is more than traditional houses in Boroujerd. The reason for this is the shape and proportions of the plan and spatial connections in the houses of Dezful.

- The concept of visual layering was measured with the variables of metric depth and step depth in this research. The visual privacy of traditional houses in Dezful is better than traditional houses in Boroujerd. In this research, to determine the visual privacy of the spaces of a set, the step relative to the input space compared to other spaces has been measured using the variables of depth and metric. This concept expresses one of the most important principles of traditional Iranian architecture, namely privacy in a spatial complex, which is more in the traditional houses of Dezful than the traditional houses of Boroujerd.

- The concept of control and access in traditional houses with an isovist variable was measured in this study. The main purpose of this variable is to create and establish a relationship between architectural spaces and descriptive and perceptible features of each space to measure the logic governing the spaces of a complex. In this study and accordance with the analysis performed, control and access in traditional houses of Dezful are significantly different from traditional houses in Boroujerd and this indicates that people in traditional houses of Dezful have a better view of their surroundings in front of traditional houses in Boroujerd.

\section{References}

Ali Al-Hesabi, M., Hosseini, S. B., \& Nasbi, F. (2012). Analysis of visual quality of residential space according to the capability and visibility of a case study: Bushehr old texture houses. Iranian Architecture, and Urban Planning, 4, 83-69.

Alitajer, S., \& Nojoumi, G. M. (2016). Privacy at home: Analysis of behavioral patterns in the spatial configuration of traditional and modern houses in the city of Hamedan based on the notion of space syntax. Frontiers of Architectural Research, 5(3), 341-352. https://doi.org/10.1016/j.foar.2016.02.003

Asefi, M., \& Imani, E. (2016). Redefining design patterns of Islamic desirable contemporary housing through qualitative evaluation of traditional homes. Iran University of Science \& Technology, 4(2), 56-73.

Bazai, M., Ghasemi Sijani, M., \& Shojaei, A. (2020). Continuity reading and change in spatial configuration of Shiraz native houses (Zandieh and Qajar) using quantitative data of UCL Depth Map software. Islamic Art, 37, 67-47.

Chegeni, F., Didehban, M., \& Hessari, P. (2020). Space configuration cognition in contemporary and traditional housing using space syntax technique (case study: Borujerd Sufian Neighborhood). Journal of Architectural Thought, 5(9).

Emo, B. (2015). Exploring isovists: The egocentric perspective. In Proceedings of the 10th International Space Syntax Symposium (Vol. 121, pp. 1-8). Space Syntax Laboratory.

Estaji, H. (2014). Flexible spatial configuration in traditional houses, the case of Sabzevar. International Journal of Contemporary Architecture "The New Arch", 1(1), 26-35.

Fisher, B. S., \& Nasar, J. L. (1992). Fear in relation to three site features: Prospect, refuge and escape. Environment and Behavior, 24(1), 35-62. https://doi.org/10.1177/0013916592241002

Goodarzi, A., \& Jalili, M. (2014). Investigating the process of formation and physical expansion of Boroujerd city [Conference presentation]. 2nd National Conference on Architecture, Civil Engineering, and Urban Environment, Hamedan.

Habitat. (2003). The Habitat Agenda goals and principles, commitments and the global plan of action. https://www.un.org/ en/events/pastevents/pdfs/habitat_agenda.pdf

Hajian, M., Alitajer, S., \& Mahdavinejad, M. J. (2020). The influence of courtyard on the formation of Iranian traditional houses configuration in Kashan. Armanshahr Magazine, 30, 55-43.

Heidari, A. A., Peyvasteh gar, Y., Mohebi nejad, S., \& Kiaee, M. (2018). Evaluation the methods of confidentiality in three Peymoon of large, small and breack in the articulation of Iranian-Islamic housing using space syntax techniques. Maremat \& Me'mari-e Iran, 1(16), 51-68.

Heidari, A., \& Peyvastegar, Y. (2018). Check the quality of the security permeability edge of space (case study: spatial analysis Timcheh structure in traditional Bazar). Honar-Ha-Ye-Ziba: Memary Va Shahrsazi, 23(1), 41-54.

Hillier, B. (2007). Space is the machine (Electronic ed.). Press Syndicate of the University of Cambrige.

Hillier, B., Honson, J., \& Peponis, J. (1984). What do we mean by building function? In J. A. Powell, I. Cooper, \& S. Lera (Eds.), Designing for building utilisation (pp. 61-72). E \& F. N. Spon Ltd.

Jeong, S., Lee, T., \& Ban, Y. (2015). Characteristics of spatial configurations in Pyongyang, North Korea. Journal of Habitat International, 47, 148-157. https://doi.org/10.1016/j.habitatint.2015.01.010

Kamalipour, H., Memarian, G. H., Faizi, M., \& Mousavian, S. M. F. (2012). Formal classification and spatial configuration in 
vernacular housing: a comparative study on the zoning of the reception area in traditional houses of Kerman province. Journal of Housing and Rural Environment, 31(138), 3-16.

Klarqvist, B. (1993). A space syntax glossary. Nordisk Arkitekturforskning, 12, 8-19.

Madahi, S. M., \& Memarian, G. H. (2019). Reading the link of spatial organization of house and lifestyle in vernacular architecture (case study: Boshrooyeh). Journal of Housing and Rural Environment, 37(164), 69-84.

Manum, B. (2009). A-graph complementary software for axialline Analysis. In Proceedings of the 7th International Space Syntax Symposium (pp. 1-7), Stockholm, Sweden.

Mohareb, N. I. (2009). Street morphology and its effect on pedestrian movement in historical Cairo. Cognitive Processing, 10(2), 253-256. https://doi.org/10.1007/s10339-009-0283-x

Mollazadeh, A., Barani Pesian, V., \& Khosrozadeh, M. (2012). The application of the space syntax of the Valiasr St Basht city. Urban Management Journal, 10(29), 81-90.

Momeni, K., Attarian, K., \& Mohebian, M. (2020). Recognition of the identity of Islamic culture in the architecture of input faces (case study: Dezful house of old texture). Journal of Architectural Thought, 7, 14-28.

Montello, D. R. (2007). The contribution of space syntax to a comprehensive theory of environmental psychology. In Proceedings of the 6th International Space Syntax Symposium (pp. 1-12), Istanbul.

Mozaffar, F., Hosseini, S. B., \& Abdemojiri, A. (2012). Culture in architectural researches. Journal of Human Rights and the Environment, 31(138), 29-38.

Mustafa, F. A., Hassan, A. S., \& Baper, S. Y. (2010). Using space syntax analysis in detecting privacy: a comparative study of traditional and modern house layouts in Erbil city, Iraq. Asian Social Science, 6(8), 157-166. https://doi.org/10.5539/ass.v6n8p157

Nasr, T. (2015). The position of the "Housing architecture" paradigm in today's image of the Islamic Iranian city. Islamic Iranian City, 2, 67-78.

Ostwald, M. J. (2011). A Justified Plan Graph analysis of the early houses (1975-1985) of Glem Murcutt. Nexus Network Journal, 13(3), 737-762. https://doi.org/10.1007/s00004-011-0089-x

Penone, C., Machon, N., Julliard, R., \& Le Viol, I. (2012). Do railway edges provide functional connectivity for plant communities in an urban context? Biological Conservation, 148(1), 126-133. https://doi.org/10.1016/j.biocon.2012.01.041
Perugia, I., Pietra, P., \& Russo, A. (2016). A plane wave virtual element method for the Helmholtz problem. ESAIM: Mathematical Modelling and Numerical Analysis, 50(3), 783-808. https://doi.org/10.1051/m2an/2015066

Pinelo, J., \& Turner, A. (2010, September 10). Introduction to UCL Depthmap (version 10.08.00r). UCL.

Rajaei, A., Keramataleh, Z., \& Abbasi Fallah, V. (2018). Evaluation of the pattern of theft crimes based on spatial configuration (case study: Varamin city). Journal of Law Enforcement Knowledge Research, 66-34.

Rodriguez, C., Lima Sakr, F., Griffiths, S., \& Hillier, B. (2012). The relationship of spatial configuration and socio-economic conditions in São Paulo, Brazil. In Proceedings of the Eighth International Space Syntax Symposium (pp. 1-24), Santiago de Chile.

Sa’adati Waqar, P., Zarghami, E., \& Qanbaran, A. A. (2020). Analysis of the interaction between the formal types of traditional houses and spatial configurations using space syntax case study: traditional houses of Kashan. Journal of Iranian Architecture Studies, 8(16), 153-179.

Sajjadzadeh, H., Izadi, M. S., \& Haghi, M. R. (2017). Recreating urban slums on spatial configuration analysis (study sample: Hamadan). Environmental Studies, 43, 1-15

Siadatian, S., \& Pourjafar, M. (2015). Testing the application of "Justified Plan Graph" (JPG) in Iranian-Islamic architecture (case studies: Rasoolian House in Yazd and a House in Masooleh). Naqshejahan-Basic Studies and New Technologies of Architecture and Planning, 4(3), 27-39.

Statistics Center of Iran. (2016). General population and housing census. Statistics Center of Iran, Tehran.

Tabatabae Malazi, F., \& Sabernejad, J. (2016). The space syntax analytical approach in understanding the configuration of Qeshm vernacular housing (case study: Laft village). Journal of Housing and Rural Environment, 35(154), 75-88

Turner, A. (2004). SalaScript manual (Depthmap version 7.09.00r).

Vannes, A. (2011). The One_ and Two_Dimensional Isovist analyses in space syntax. Research in Urbanism, (2), 167-170.

Weisman, J. (1981). Evaluating architectural legibility: way-finding in in the built. Environment and Behavior, 13(2), 189-204. https://doi.org/10.1177/0013916581132004

Zolfagharzadeh, H., \& Hessari, P. (2014). Ecological view to the architecture of habitats. Journal of Housing and Rural Environment, 33(145), 29-44. 